\title{
Perinatal Distress Leads to Lateralized Medial Prefrontal Cortical Dopamine Hypofunction in Adult Rats
}

\author{
Wayne G. Brake, ${ }^{1}$ Ron M. Sullivan, ${ }^{2}$ and Alain Gratton ${ }^{2}$ \\ 1 Laboratory of Neuroendocrinology, The Rockefeller University, New York, New York 10021, and 2Douglas Hospital \\ Research Centre, Department of Psychiatry, McGill University, Montréal, Canada H4H 1R3
}

\begin{abstract}
Obstetric complications involving anoxia or prolonged hypoxia are suspected to increase the risk for such mental disorders as schizophrenia and attention deficit-hyperactivity disorder. In previous studies, we reported evidence of enhanced nucleus accumbens (NAcc) dopamine (DA) function in adult rats subjected to intrauterine anoxia during cesarean $(C)$ section birth. In the present study, we used voltammetry and monoamine-sensitive electrodes to investigate the possibility that this functional hyperactivity of the meso-NAcc system is attributable to a loss of inhibitory control from the medial prefrontal cortex (PFC). We monitored the DA responses to repeated once-daily stress in the right or left PFC of adult male rats born vaginally (VAG) or by $C$-section, either with $(C+15)$ or without $(C+0)$ an additional 15 min of intrauterine anoxia. In $\mathrm{C}+15$ animals, we observed a pronounced and persistent blunting of stress-induced DA release
\end{abstract}

in the right PFC but not in the left; with repeated testing, a similar pattern of dampened right PFC DA stress responses emerged in $\mathrm{C}+\mathrm{O}$ animals. In addition, $\mathrm{C}+15$ animals were spontaneously more active than VAG and $\mathrm{C}+0$ animals and displayed an increase in PFC DA transporter density that was also lateralized to the right hemisphere. There was no evidence, however, that PFC $D_{1}$ and $D_{2}$ receptor levels differed between birth groups or hemisphere. These findings suggest a mechanism by which perinatal complications involving anoxia might contribute to the etiology of mental disorders that have been linked to disturbances in central DA transmission and lateralized PFC dysfunction.

Key words: stress; voltammetry; cesarean section; anoxia; obstetric complications; dopamine transporter; asymmetry; attention deficit/hyperactivity disorder
Obstetric complications at or close to the time of birth have long been thought to increase the risk for some mental disorders (Hartsough and Lambert, 1985; Lewis and Murray, 1987; Norman and Malla, 1993; Verdoux and Bourgeois, 1993; Günther-Genta et al., 1994; Milberger et al., 1997). Such complications are suspected to produce subtle changes in brain maturation, the impact of which may become apparent only much later in life. One consequence common to many obstetric problems is an episode of anoxia or hypoxia to the fetus. Using a delayed cesarean (C) section procedure in rats, we found evidence that perinatal complications involving anoxia can lead to alterations in central dopamine (DA) function during adulthood that are consistent with the postulated pathophysiology of schizophrenia and other disorders, most notably attention deficit-hyperactivity disorder (ADHD) (Weinberger, 1987; Castellanos, 1997). Specifically, we showed that the acute nucleus accumbens (NAcc) DA response to repeated stress is greater in adult rats born by $\mathrm{C}$ section than in vaginally born controls and even more so when the animals had sustained an anoxic episode during cesarean delivery (Brake et al., 1997b). Moreover, these animals would sensitize to the locomotor stimulant action of amphetamine after being stressed under conditions that failed to sensitize vaginally born controls (Brake et al., 1997a). These findings suggested that, under certain conditions, fetal distress at birth can trigger neurodevelopmental changes that eventually result in increased mesolimbic DA responsiveness.

The development of NAcc DA hyperfunction, we reasoned, might reflect a loss of inhibitory control from DA-sensitive afferents originating in the medial prefrontal cortex (PFC) where stress will also activate DA transmission (Deutch, 1992; Abercrombie et

\footnotetext{
Received Feb. 14, 2000; revised April 6, 2000; accepted May 3, 2000.

This study was supported by a Medical Research Council of Canada (MRC) grant to A.G., National Alliance for Research on Schizophrenia and Depression awards to A.G. and R.M.S., and an MRC fellowship to W.G.B.

Correspondence should be addressed to Alain Gratton, Douglas Hospital Research Centre, 6875 LaSalle Boulevard, Verdun, Québec, Canada H4H 1R3. E-mail: gratal@douglas.mcgill.ca.

Copyright (C) 2000 Society for Neuroscience $0270-6474 / 00 / 205538-06 \$ 15.00 / 0$
}

al., 1989; Doherty and Gratton, 1996). The PFC plays a pivotal role in so-called executive functions. Specialized neurons within the PFC are involved in maintaining task-relevant information "on line" for brief periods (Fuster, 1997). These neurons are part of the circuitry that subserves processes related to working memory and sustained attention, both essential components for structuring goaldirected behaviors. Dopamine plays a modulatory role here by optimizing the activity of PFC neurons and the functions they subserve (Williams and Goldman-Rakic, 1995; Murphy et al., 1996). Not surprisingly, disorders of higher executive function often reflect disruptions of prefrontal cortical and DA systems.

Thus, the purpose of the present study was to investigate how PFC DA function is affected in adult animals subjected to intrauterine anoxia during $\mathrm{C}$ section delivery. Based on our recent findings in neonatally PFC-lesioned rats (Brake et al., 2000), we hypothesized that the enhanced NAcc DA stress response seen in these animals reflects, at least in part, impaired DA transmission in PFC. To test this idea, we used voltammetry to monitor the acute PFC DA responses to repeated, once-daily stress. We also used quantitative receptor autoradiography to examine possible changes in PFC DA $D_{1}$ and $D_{2}$ receptors and DA transporter (DAT) levels. There is accumulating evidence that the PFC is functionally lateralized with respect to the regulation of stress responses (Sullivan and Gratton, 1999), and the left and right mesocortical DA projections have been shown to be differentially involved in numerous aspects of stress-related processes (Carlson et al., 1993, 1996; Sullivan and Szechtman, 1995; Sullivan and Gratton, 1998; Berridge et al., 1999). Consequently, we examined DA stress responses and DAT $D_{1}$ and $D_{2}$ receptor binding in left and right PFC separately.

\section{MATERIALS AND METHODS}

Animals and intrauterine anoxia. All procedures were performed in accordance with the guidelines established by the Canadian Council on Animal Care and the Society for Neuroscience Policy on the Use of Animals in Research. Rats were delivered via $\mathrm{C}$ section and asphyxiated according to methods modified from those first reported by Bjelke et al. (1991); a detailed description of the procedure has been published previously (Brake et al., 1997a,b). On the day of parturition, Sprague Dawley dams (Charles 
River, St. Constant, Quebec, Canada) were decapitated and hysterectomized, and the isolated intact uterus was immediately immersed in a $37^{\circ} \mathrm{C}$ saline bath for $13.5 \mathrm{~min}$. The pups were then delivered from the uterus and, if necessary, gently palpated to initiate breathing. The period of anoxia was defined as the time the uterus was immersed in the saline bath to the moment the pups began breathing on their own. Therefore, the animals that had been subjected to birth anoxia were designated $\mathrm{C}$ section +15 min of anoxia $(\mathrm{C}+15)$.

The extent of asphytic insult in $\mathrm{C}+15$ animals is less severe than it appears; compared with humans, the rat brain at birth is more resistant to anoxia (Jilek et al., 1970). It is worth noting, however, that although anoxia during human birth is carefully monitored, severe hypoxemia may still occur in preterm infants without observable changes in breathing or heart rate (Hales et al., 1993; Poets et al., 1995). It should be emphasized also that rats are born at an earlier ontogenic stage than humans and would more closely parallel the premature infant (Romijin et al., 1991).

A second group of animals comprised pups born by $\mathrm{C}$ section with no added period of anoxia $(C+0)$. These animals were delivered immediately after removing the uterus from the dam. Both groups of pups delivered by $\mathrm{C}$ section were placed on a heating pad until they had fully recovered and were breathing regularly. A third group of animals comprised pups that were born vaginally (VAG).

A code consisting of a small amount of indelible (India) ink that was injected into one of the paws was used to later identify birthing condition. All pups were cross-fostered with surrogate dams in litters of 10 pups per dam, and each litter comprised pups from each of the three birth groups. Only male pups were included in the study to avoid confounding group effects with sex differences. Upon weaning at $21 \mathrm{~d}$, animals were randomly paired and housed on a $12 \mathrm{hr}$ light/dark cycle (lights on at 8:00 A.M.) with food and water available ad libitum.

Surgery. At 3-4 months of age, animals from each of the three birth conditions were pretreated with atropine sulfate $(0.1 \mathrm{mg} / \mathrm{kg}$, i.p.), anesthetized with sodium pentobarbital $(60 \mathrm{mg} / \mathrm{kg}$, i.p.), and implanted under stereotaxic guidance with a voltammetric recording electrode aimed at either the right or left PFC (prelimbic/infralimbic cortex); the coordinates were $3.2 \mathrm{~mm}$ anterior to bregma, $\pm 0.6 \mathrm{~mm}$ lateral to the midline, and 4.2 $\mathrm{mm}$ below the cortical surface (Paxinos and Watson, 1985). All animals were also implanted with a $\mathrm{Ag} / \mathrm{AgCl}$ reference electrode and a stainless steel ground wire in the contralateral and ipsilateral parietal cortex, respectively. Miniature pin connectors soldered to the electrochemical and reference electrodes and ground wire were inserted into a plastic strip connector that was then anchored with acrylic dental cement to four stainless steel screws threaded into the cranium.

Electrochemical probes. The electrochemical probes each comprised three 30- $\mu \mathrm{m}$-diameter carbon fibers (Avco Specialty Materials, Lowell, MA) that extended $50-100 \mu \mathrm{m}$ beyond the sealed tip of a pulled glass capillary. The exposed fiber bundle was repeatedly coated with a 5\% solution of the ion exchange polymer Nafion (Aldrich, Milwaukee, WI). Electrodes were calibrated immediately before implantation to determine their sensitivity to DA and their selectivity for DA against ascorbic acid. Only electrodes with a DA to ascorbic acid selectivity ratio greater than 1000:1 and a linear response $(r \geq 0.997)$ to increasing concentrations of DA were used.

Electrochemical measurements. Electrochemical recordings were performed using a computer-controlled chronocoulometric system (Medical Systems Corp., Greenvale, NY). An oxidative potential of $+55 \mathrm{~V}$, with respect to the reference electrode, was applied to the electrode for 100 msec at a rate of $5 \mathrm{~Hz}$. The amplitude of the resulting oxidation curren was digitized and integrated over the last $80 \mathrm{msec}$ of each pulse. Every 10 digitized measures of current were summed and converted on-line to equivalent values of DA concentration using the in vitro calibration factor for each respective electrode (for a detailed description, see Brake et al., 1997b, 1999; Doherty and Gratton, 1992, 1996, 1997).

Animals were tested in a sound-attenuating recording chamber with a glass façade; the animals had been acclimatized to the recording chamber for $2-3 \mathrm{hr}$ before surgery. Two days after surgery, animals were placed in the recording chamber and connected to the recording apparatus via shielded cable and low-impedance commutator (Airflyte, Bayonne, NJ). A preamplifier (gain of $1 \times 10^{8}$ ) was connected directly onto the animal's head assembly to minimize electrical interference. Baseline electrochemical signals were recorded for $\sim 160 \mathrm{~min}$ on the first test day. On each of the 5 subsequent days, stable baseline recordings were obtained for $20-30 \mathrm{~min}$, after which animals were stressed by placing a wooden clothespin $\sim 1.5 \mathrm{~cm}$ from the base of the tail for $15 \mathrm{~min}$. Recordings were performed until the electrochemical signal returned to baseline (prestress) levels.

Histology. At the conclusion of the experiment, animals were deeply anesthetized with sodium pentobarbital ( $75 \mathrm{mg} / \mathrm{kg}$, i.p.) and transcardially perfused with $0.9 \%$ saline, followed by a $10 \%$ formalin solution. The brains were stored in $10 \%$ formalin and subsequently cryoprotected in a $30 \%$ sucrose-formalin solution before being sliced. Electrode placements were confirmed from $40 \mu \mathrm{m}$ thionin-stained coronal sections.

Electrochemical data format and analysis. Because of the inherent differences in sensitivity between Nafion-coated electrodes, in vivo changes in oxidation current recorded with different electrodes (in different animals) cannot be assumed to be equivalent. Thus, valid comparisons are possible only if the sensitivity of each electrode is calibrated against a standard and the electrochemical data are expressed as standard equivalent values. In the present study, DA was used as the standard to calibrate electrode sensitivity. Accordingly, in vivo changes in oxidation current are expressed as micromolar equivalent values of DA concentration. Averaged data are presented as micromolar DA equivalent changes in electrochemical signal relative to the signal level at the onset of the stress period (time 0 ). Because the record at time 0 was the reference point for changes in electrochemical signal that followed, it was given a value of 0 . A value of $0 \mu \mathrm{M}$, therefore, is not meant to correspond to the absolute concentration of extracellular DA. Rather, the data reflect relative changes in the DA signal elicited by stress. Statistical comparisons were based on group differences in the amplitude of electrochemical signal increases taken at 5 min intervals from onset of tail-pinch stress. An overall four-way mixed factorial ANOVA with hemisphere (left or right PFC) and birth group (VAG, C + 0, or C + $15)$ as between-subject factors and test day (days 1-5) and time from stress onset ( $70 \mathrm{~min}$ at $5 \mathrm{~min}$ intervals) as within-subject factors was conducted to uncover any significant effect of repeated once-daily exposures to stress. However, because the magnitude of the DA stress response was known $a$ priori to be experience-dependent (Doherty and Gratton, 1992), data obtained on day 1 , when animals were naïve to experimental conditions, were analyzed separately from those obtained on days $2-5$. For this purpose, the effects of birth group, hemisphere, and time from stress onset were assessed using a three-way mixed factorial ANOVA. When indicated, post hoc analyses were conducted using Tukey's honestly significant difference (HSD) test.

Locomotor activity. Birth group differences in spontaneous locomotor activity were assessed in a separate cohort of 36 randomly selected, experimentally naïve 3 -month-old animals ( $n=12$ per birth group). The animals were placed in activity chambers $(30 \times 40 \times 40 \mathrm{~cm})$ for $2 \mathrm{hr} / \mathrm{d}$ for 5 consecutive days; the animals had been allowed to acclimatize to their respective chambers on two separate occasions before testing. The 12 chambers were housed in a dimmed room and were each equipped with two photoelectric switches; consecutive interruptions of the two light beams were monitored and stored by a computer. Each animal was tested at the same time of the dark phase of its diurnal cycle (between 9:00 A.M. and 2:00 P.M.). To avoid confounding spontaneous locomotor activity with novelty-induced activity, each animal was tested in the same chamber throughout the experiment. The data are expressed as mean photobeam interruptions per $10 \mathrm{~min}$ interval. The data were collapsed across test days, and group differences were tested using a mixed factorial ANOVA and post hoc comparisons (Tukey's HSD).

Quantitative receptor autoradiography. Tissue used for receptor autoradiography was taken from separate groups of experimentally naïve animals ( $n=6-8$ per birth group). At 3 months of age, animals were decapitated, and the brains were rapidly removed, frozen in isopentane, and then stored at $-80^{\circ} \mathrm{C}$. Brains were sliced in serial $16 \mu \mathrm{m}$ coronal sections, which were mounted on glass slides (two sections per slide), desiccated under vacuum at $4^{\circ} \mathrm{C}$ overnight, and then stored at $-80^{\circ} \mathrm{C}$ until used.

For DAT binding, sections were preincubated for $20 \mathrm{~min}$ in ice-cold 50 $\mathrm{mm}$ Tris $\mathrm{HCl}$ buffer, $\mathrm{pH} 7.0$, containing $120 \mathrm{~mm} \mathrm{NaCl}$. Total binding was measured from four sections that had been incubated for $60 \mathrm{~min}$ in the same ice-cold buffer to which was added 10 nM $\left[{ }^{3} \mathrm{H}\right] N-[1-(-2-$ benzo(b)thiophenyl)cyclohexyl]piperidin ([ $\left.\left.{ }^{3} \mathrm{H}\right] \mathrm{BTCP}\right)$ (DuPont NEN, Boston MA), a specific DAT ligand ( $K \mathrm{~d}$ of $0.9 \mathrm{~nm}$ for high-affinity uptake site) (Vignon et al., 1988; Katz et al., 2000). Nonspecific binding was determined from two adjacent sections by adding $1 \mathrm{mM}$ GBR12935 to the binding buffer. Sections were subsequently washed in ice-cold buffer (four times for $5 \mathrm{~min}$ each), rinsed in ice-cold distilled water, and left to dry overnight.

$\mathrm{D}_{1}$-like receptor binding was measured from sections preincubated at room temperature for $20 \mathrm{~min}$ in $50 \mathrm{~mm}$ Tris $\mathrm{HCl}$ buffer, $\mathrm{pH}$ 7.4, containing $120 \mathrm{~mm} \mathrm{NaCl}, 5 \mathrm{~mm} \mathrm{KCl}$, and $0.1 \%$ ascorbic acid. Sections $(n=4)$ were then incubated for $60 \mathrm{~min}$ in the same buffer to which was added $2 \mathrm{~nm}$ $\left[{ }^{3} \mathrm{H}\right] \mathrm{SCH} 23390$ (DuPont NEN) and $30 \mathrm{~nm}$ ketanserine to prevent binding to serotonergic receptors. Nonspecific binding was determined from two adjacent sections by adding $1 \mu \mathrm{M}(+)$-butaclamol to the buffer. Total $\mathrm{D}_{2}$-like receptor binding was determined by incubating sections $(n=4)$ for $60 \mathrm{~min}$ at room temperature in $50 \mathrm{~mm}$ Tris $\mathrm{HCl}$ buffer, $\mathrm{pH}$ 7.4, containing $120 \mathrm{~mm} \mathrm{NaCl}, 5 \mathrm{~mm} \mathrm{KCl}, 0.1 \%$ ascorbic acid, and $5.7 \mathrm{~nm}\left[{ }^{3} \mathrm{H}\right]$ Raclopride (DuPont NEN). Nonspecific binding was assessed from adjacent sections that were incubated in the same buffer containing $1 \mu \mathrm{M}(+)$-butaclamol. Sections used for $\mathrm{D}_{1}$-like and $\mathrm{D}_{2}$-like receptor binding were washed in ice-cold buffer (three times for $5 \mathrm{~min}$ each), rinsed in ice-cold distilled water, and left to dry overnight.

Brain sections were apposed to tritium-sensitive Hyperfilm (Amersham Pharmacia Biotech, Toronto, Ontario, Canada) alongside microscalecalibrated tritium standards (Amersham Pharmacia Biotech); exposure times for $\left[{ }^{3} \mathrm{H}\right] \mathrm{BTCP},\left[{ }^{3} \mathrm{H}\right] \mathrm{SCH} 23390$, and $\left[{ }^{3} \mathrm{H}\right]$ Raclopride were 7,25 , and $14 \mathrm{~d}$, respectively. Autoradiograms were analyzed with a computerized image-analysis system (MCID-M4; Imaging Research, St. Catherine's, Ontario, Canada), and binding densities were converted to femtomoles per milligram protein based on the tritium standard calibration and the specific activity of each respective ligand. For each animal, specific $\mathrm{D}_{1}$-like and $\mathrm{D}_{2}$-like receptor and DAT binding was calculated by subtracting the averaged nonspecific binding ( $n=2$ sections) from the averaged total binding ( $n=4$ sections). Birth group and hemispheric differences in DA receptor and DAT binding were assessed for significance using a two-way 


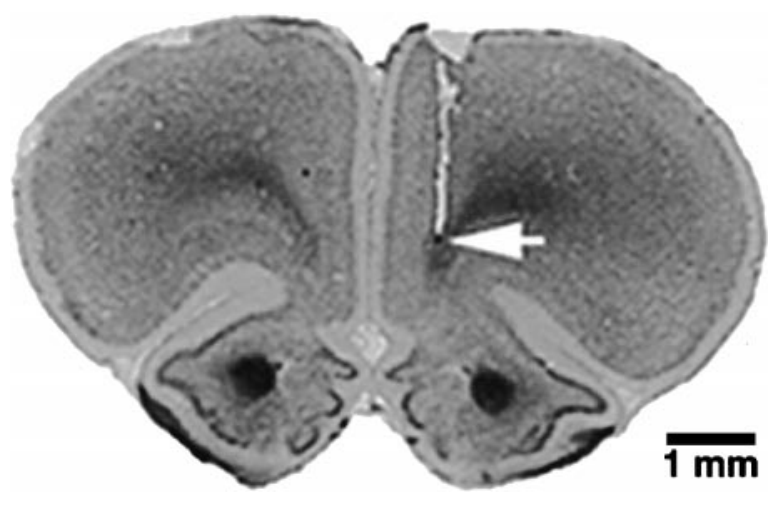

Figure 1. Photomicrograph of tissue damage produced by a typical electrode placement in the right PFC. Arrow indicates point of deepest electrode penetration.

ANOVA, followed by planned comparisons based on the results of the electrochemical recording experiment.

\section{RESULTS}

\section{PFC dopamine response to stress}

Nineteen animals with histologically confirmed electrode placements in the left PFC (VAG, $n=6 ; \mathrm{C}+0, n=6 ; \mathrm{C}+15, n=7$ ) and 17 animals with confirmed placements in the right PFC (VAG, $n=6 ; \mathrm{C}+0, n=6 ; \mathrm{C}+15, n=5)$ were included in the data analysis (Fig. 1). Based on the atlas of Paxinos and Watson (1985), the point of deepest electrode penetration was estimated in all cases to be within the infralimbic or ventral prelimbic region of the PFC.

Figure 2 shows for the three birth groups of animals the mean increases in DA signal recorded in the left and right PFC on each of the 5 test days. Analysis of the stress-induced DA signal increases recorded on day 1 , when animals were naïve to experimental conditions, revealed a significant interaction between birth group and hemisphere $\left(F_{(2,30)}=3.504, p=0.0429\right)$. Post hoc comparisons indicated that stress-induced signal increases recorded in the right PFC of $\mathrm{C}+15$ animals were significantly smaller than those recorded in the same hemisphere of $\mathrm{C}+0$ and VAG animals $(p<0.05)$. There were no such group differences in the magnitude of the stress responses recorded in the left PFC.

A four-way ANOVA of the entire data set (days 1-5) indicated that there was no significant effect of test day, nor was there a significant interaction between test day and any of the other variables (birth group, hemisphere, and time from stress onset). Thus, the data collected from each animal were collapsed across test days, and a three-way ANOVA was conducted with birth group and hemisphere as between-subject factors and time from stress onset as the within-subject factor. This analysis uncovered a significant three-way interaction between birth group, hemisphere, and time from stress onset $\left(F_{(26,2262)}=3.788, p<0.0001\right)$. Post hoc analysis revealed that DA stress responses recorded in the right $\mathrm{PFC}$ of both $\mathrm{C}+0$ and $\mathrm{C}+15$ animals were significantly attenuated compared with the right PFC stress responses of VAG animals $(p<0.05)$. No such group differences were observed in the left hemisphere where stress-induced DA signal increases were often greater but also considerably more variable than in the right PFC; although unexplained, this difference has been reported by others (Maisonneuve et al., 1990).

\section{Spontaneous locomotor activity}

Figure 3 presents the within-session changes in spontaneous locomotor activity of VAG, $\mathrm{C}+0$, and $\mathrm{C}+15$ animals. Compared with animals of the other two birth groups, $\mathrm{C}+15$ animals were, overall, significantly more active during the initial $50 \mathrm{~min}$ of the session $\left(F_{(22,1947)}=2.107, p=0.0019\right)$.

\section{DA receptors and transporter}

Significant birth group differences in DAT binding were observed in the right but not the left $\operatorname{PFC}\left(F_{(2,21)}=3.686, p=0.037\right)$.
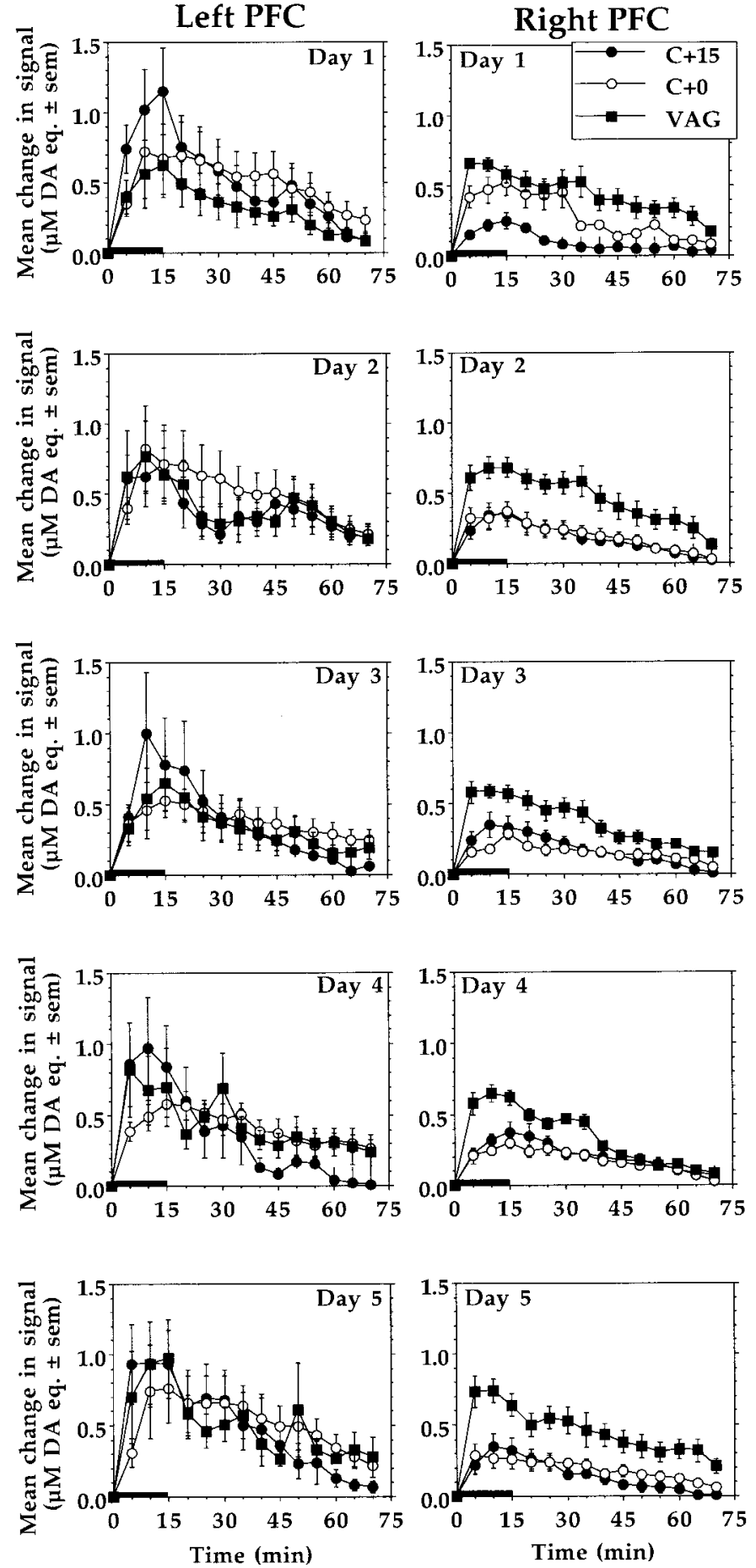

Figure 2. Mean \pm SEM increases of DA signals recorded in left and right PFC in response to each of five once-daily episodes of tail-pinch stress. Overall, the right but not the left PFC DA stress responses in $C+15$ and $\mathrm{C}+0$ animals were significantly smaller than in VAG controls $(p<0.01$; Tukey's HSD). However, on the first test day, right PFC DA responses were significantly attenuated only in $\mathrm{C}+15$ animals ( $p<0.05$; Tukey's HSD). Length of horizontal bar corresponds to the duration of the stress period.

Specifically, the density of $\left[{ }^{3} \mathrm{H}\right] \mathrm{BTCP}$-labeled sites in the right PFC was higher in $\mathrm{C}+15$ animals than in VAG controls $(p<0.05)$; the DAT binding density in right PFC of $\mathrm{C}+0$ animals was also higher relative to controls but not significantly so. There were no significant differences in PFC $\mathrm{D}_{1}$-like and $\mathrm{D}_{2}$-like receptor binding between the three birth groups or the left and right hemispheres (Table 1). 


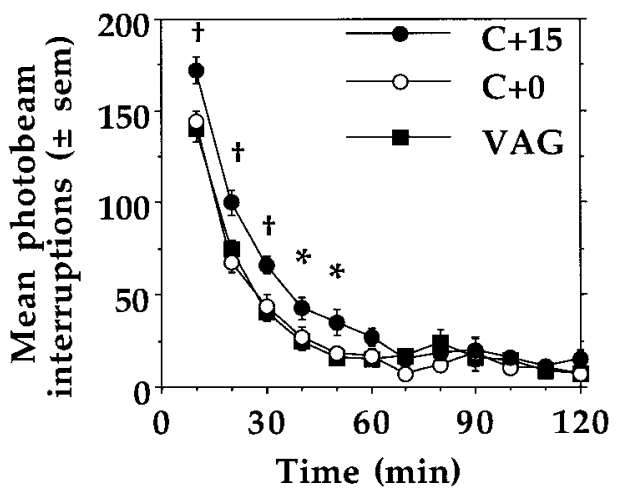

Figure 3. Mean \pm SEM spontaneous locomotor activity scores of VAG, C +0 , and $\mathrm{C}+15$ animals ( $n=12$ per group). Across the 5 test days, $\mathrm{C}+$ 15 animals were more active than VAG and $C+0$ animals during the initial $50 \mathrm{~min}$ of the session ( ${ }^{*} p<0.05 ; \uparrow p<0.01$; Tukey's HSD).

\begin{tabular}{|c|c|c|}
\hline & Left PFC & Right PFC \\
\hline \multicolumn{3}{|c|}{$\mathrm{D}_{1}$-like receptors $\left[{ }^{3} \mathrm{H}\right] \mathrm{SCH} 23390$} \\
\hline VAG & $16.7 \pm 1.98$ & $16.2 \pm 1.74$ \\
\hline $\mathrm{C}+0$ & $23.3 \pm 4.76$ & $21.6 \pm 3.98$ \\
\hline $\mathrm{C}+15$ & $21.5 \pm 2.10$ & $19.5 \pm 1.77$ \\
\hline \multicolumn{3}{|c|}{$\mathrm{D}_{2}$-like receptors $\left[{ }^{3} \mathrm{H}\right]$ Raclopride } \\
\hline VAG & $1.92 \pm 0.22$ & $1.99 \pm 0.38$ \\
\hline $\mathrm{C}+0$ & $2.49 \pm 0.48$ & $2.61 \pm 0.45$ \\
\hline $\mathrm{C}+15$ & $3.24 \pm 1.06$ & $2.12 \pm 0.58$ \\
\hline \multicolumn{3}{|c|}{ DA transporter $\left[{ }^{3} \mathrm{H}\right] \mathrm{BTCP}$} \\
\hline VAG & $33.5 \pm 4.97$ & $25.7 \pm 5.89$ \\
\hline $\mathrm{C}+0$ & $47.7 \pm 7.43$ & $31.9 \pm 7.85$ \\
\hline $\mathrm{C}+15$ & $39.5 \pm 7.04$ & $53.1 \pm 10.40^{*}$ \\
\hline
\end{tabular}

Dopamine receptor and transporter levels are expressed in femtomoles per milligram wet tissue. Values are means \pm SEM of six to eight animals from each birth group $\left({ }^{*} p<0.05\right.$, Scheffe's $\mathrm{C}+15$ vs VAG in right PFC).

\section{DISCUSSION}

The main finding of the present study is that perinatal distress $(\mathrm{C}$ section plus anoxia) leads to a lateralized suppression of stressinduced activation of PFC DA transmission during adulthood. This developmental insult is also associated with long-lasting changes in DAT levels in the right PFC and with behavioral hyperactivity. When stressed for the first time (day 1), a blunted right PFC DA response was seen only in animals that had been asphyxiated during $\mathrm{C}$ section delivery $(\mathrm{C}+15$ group). However, with each subsequent daily exposure to stress, the same pattern emerged in $\mathrm{C}$ section alone $(\mathbf{C}+0)$ animals, suggesting that the lateralized PFC deficit is, in part, experience-dependent. That the present procedures, which induce a mesocortical DA deficit, also result in subcortical (mesolimbic) DA hyperfunction (Brake et al., 1997a,b) is consistent with a large body of evidence demonstrating that mesocortical DA exerts a tonic inhibitory influence on subcortical DA function (Pycock et al., 1980; Deutch, 1992; Mitchell and Gratton, 1992; Rosin et al., 1992; Doherty and Gratton, 1996; Banks and Gratton, 1995; Carr et al., 1999).

The long-term effects of perinatal anoxia on PFC DA were also examined in a study by El-Khodor and Boksa (1997), who observed a significant reduction of steady-state DA levels in PFC of $\mathrm{C}+0$ but not $\mathrm{C}+15$ animals, suggesting that adult PFC DA function is more profoundly altered as a result of $\mathrm{C}$ section birth than our data would indicate. The significance of this finding in the context of the present study is difficult to assess, however. El-Khodor and Boksa (1997) also reported that PFC DA metabolite levels were unaffected by conditions at birth, indicating that the decreases in tissue
DA levels they observed in $\mathrm{C}+0$ animals reflect altered intracellular DA accumulation rather than increased DA release. Interpretation is further complicated by the fact that the data of El-Khodor and Boksa (1997) were obtained from both the left and right PFC; thus, the extent to which these changes in PFC DA metabolism might be lateralized remains to be examined. Interestingly, in this context, depletion of DA in the right but not left PFC results in bilateral increases in striatal DA turnover ratios (Sullivan and Szechtman, 1995).

We also observed differences between birth groups in DAT levels, and these too were evident only in the right PFC. In contrast, there was no evidence that $\mathrm{D}_{1}$-like and $\mathrm{D}_{2}$-like receptor levels differed between birth groups or hemisphere. The lateralized increase in right PFC DAT levels could explain the blunted DA response observed there, given that reuptake is the primary mechanism of extracellular DA clearance and that DA transmission is extremely sensitive to changes in DAT density or kinetics (Wightman and Zimmerman, 1990). Although the effect was not statistically significant, right PFC DAT levels in $\mathrm{C}+0$ animals were also comparatively higher than in VAG controls. Whether this marginal increase in DAT density is functionally relevant to the progressive day-to-day decrease of right PFC stress response seen in $\mathrm{C}+0$ animal is unclear at present. Because the tissue used for autoradiography was taken from naïve animals, it also remains to be determined whether PFC DAT levels in $\mathrm{C}+0($ and $\mathrm{C}+15)$ animals would differ after repeated daily exposure to stress.

Rats subjected to perinatal anoxia were found to be persistently hyperactive, as our previous study suggested (Brake et al., 1997a). The fact that the hyperactivity was expressed during the first hour of each session possibly suggests a heightened response to novelty, a failure to habituate to the testing environment, or an impaired ability to inhibit exploratory activity. Whatever the underlying deficit may be, it is clear from the locomotor activity data that its behavioral consequences are seen only when animals sustained an anoxic episode during $\mathrm{C}$ section delivery. Why $\mathrm{C}+0$ animals were not also hyperactive is unclear at present. A variety of procedures inducing perinatal anoxic states in rats have been shown to result in behavioral hyperactivity that peaks during the juvenile period and declines toward the time of puberty (Speiser et al., 1983, 1988). In addition, such treatments produce lasting deficits in spatial memory (Dell'Anna et al., 1991) and discrimination learning (Hershkowitz et al., 1983). Given the observed asymmetrical cortical alterations, it is noteworthy that a variety of experimentally induced deficits in the right, but not left hemisphere, including frontal 6-hydroxydopamine lesions, induce locomotor hyperactivity (Robinson, 1979; Robinson and Stitt, 1981; Kubos et al., 1982).

As mentioned earlier, birth complications involving hypoxic or anoxic states are commonly cited as risk factors for such disorders as schizophrenia and ADHD. Insofar as each condition has been hypothesized to involve a mesocortical DA deficit in conjunction with hyperfunctional subcortical DA systems (Davis et al., 1991; Deutch, 1992; Castellanos, 1997), the present results lend credence to an etiological link with birth complications. However, there are many reasons to believe that the pattern of lateralized cortical changes reported here has special relevance to ADHD.

In addition to the reciprocal changes in cortical/subcortical DA function and associated behavioral hyperactivity, several clinical studies have demonstrated right hemispheric deficits in ADHD (Carter et al., 1995; Nigg et al., 1997). Imaging studies have revealed anatomical and functional deficits in prefrontal-striatal circuitry in the right hemisphere, correlating with symptomology (Casey et al., 1997; Castellanos, 1997). Based on their observations, Heilman et al. (1991) have specifically proposed that ADHD reflects an impairment in right hemispheric mesocortical DA function, and asymmetrical DA metabolism in the PFC of ADHD subjects has been demonstrated (Ernst et al., 1998). Notably, it has been shown in rats that DA turnover in the right PFC is positively correlated with performance in tasks of sustained attention (Puumala and Sirviö, 1998).

The present finding of elevated DAT levels in the right PFC is 
also significant in this regard. The standard treatment for ADHD is methylphenidate (Ritalin), which acts at the DAT by blocking DA uptake, thus increasing the availability of synaptic DA. In humans, genetic studies have shown links between anomalies in the DAT gene and ADHD (Cook et al., 1995; Gill et al., 1997), and knock-out mice lacking the DAT gene have been proposed as an animal model of ADHD based primarily on their profound hyperactivity and response to psychostimulants (Gainetdinov, 1999). The present results suggest that far more subtle, localized, and lateralized alterations in DAT may be associated with a spectrum of changes characteristic of ADHD. Such changes are induced by early developmental insult and may become manifest through similar, if not common, mechanisms as those that are affected in genetically predisposed individuals. Interestingly, obstetric complications are predictive of ADHD diagnosis in both familial and nonfamilial forms of the disorder (Milberger et al., 1997).

The present birth manipulations could alter cortical development and maturation in several ways. The timing of any developmental insult is important in determining the type of long-term damage incurred and the particular afferent systems affected. In the rat, cortical DA afferents begin reaching their cortical targets earlier (approximately the final trimester of gestation) and achieve their adult innervation pattern later ( 2 months postnatal) than other major cortical afferent systems (Berger-Sweeney and Hohmann, 1997). The window of vulnerability of this system to developmental insults is therefore particularly long. Moreover, this system develops faster in females than males, possibly conferring a prolonged vulnerability to insult in the latter; presumably, this might contribute to the higher incidence among males of neurodevelopmental disorders such as ADHD.

Additionally, the same perinatal manipulation as presently used is known to cause dysregulation of plasma hormone (glucocorticoid) physiology in the first weeks of life (Boksa, 1997). There is a high density of steroid receptors in PFC and hippocampus, which are overexpressed at approximately the time of birth (MacLusky et al., 1979; Meaney et al., 1985; McEwen, 1992). Glucocorticoids affect both cell death and neurogenesis in the hippocampus during this developmental phase (Gould et al., 1991a,b), although such actions have not been investigated in PFC. Cesarean section birth with anoxia, however, does increase cell death in PFC by postnatal day 8 in the rat (Dell'Anna et al., 1997). Finally, glucocorticoid receptors are also colocalized in DA-containing cell bodies of the ventral tegmental area, the origin of the mesocortical DA innervation (Harfstrand et al., 1986), potentially affecting development of this projection system.

The asymmetrical nature of the cortical changes reported here is striking, although not surprising. The mesocortical DA system in the adult rat can exhibit considerable functional lateralization in such things as regulation of stress responses (Carlson et al., 1993; Sullivan and Gratton, 1998; Berridge et al., 1999), drug selfadministration (Glick et al., 1994; Nielsen et al., 1999), and subcortical DA function (Sullivan and Szechtman, 1995; Carlson et al., 1996). Cerebral DA asymmetries are present from the time of birth (Afonso et al., 1993; Rodriguez et al., 1994; Varlinskaya et al., 1995). Also, given the different rates of human cortical maturation of the two hemispheres (Geshwind and Galaburda, 1987), it should not be surprising that long-term sequelae of early developmental insults would be asymmetrical as well.

That perinatal anoxia affected only the right PFC may reflect the intrinsic specialization of this structure in regulating physiological stress responses in the rat (Sullivan and Gratton, 1999). Differences in the degree of fetal or neonatal physiological distress, either acutely or cumulatively, might therefore preferentially impact on maturational processes within this brain region. Mesocortical DA innervation, particularly in the right PFC, is thought to play an important role in optimizing adaptive responses to stressful conditions (Sullivan and Szechtman, 1995; Sullivan and Gratton, 1998; Berridge et al., 1999). It is perhaps then not a coincidence that blunted or suboptimal plasma glucocorticoid stress responses are seen not only in adult rats subjected to perinatal anoxia (Boksa et al., 1996) but also in ADHD subjects with "developmentally persistent" forms of the disorder (King et al., 1998). Hence, compromising the development of the right PFC would ultimately be expected to disrupt those processes normally subserved by this region, be they adapting to stress, behavioral inhibition, regulation of subcortical systems, or higher executive and attentional functions.

In summary, perinatal distress involving anoxia induces lasting changes in mesocortical DA function and behavior. Together with other findings, it is suggested here that highly selective and lateralized changes in PFC may be primary in contributing to an observed spectrum of changes associated with this developmental challenge. Although the present manipulations are not intended to model a specific disease state, parallels with the clinical features of neurodevelopmental disorders such as ADHD are numerous and intriguing. These findings implicate mechanisms by which perinatal distress could lead to clinically reported outcomes and generate testable hypotheses concerning the long-term behavioral consequences of perinatal trauma.

\section{REFERENCES}

Abercrombie ED, Keefe KA, DiFrischia DS, Zigmond MJ (1989) Differential effect of stress on in vivo dopamine release in striatum, nucleus accumbens, and medial frontal cortex. J Neurochem 52:1655-1658.

Afonso D, Santana C, Rodriguez M (1993) Neonatal lateralization of behavior and brain dopaminergic asymmetry. Brain Res Bull 32:11-16.

Banks KE, Gratton A (1995) Possible involvement of prefrontal cortex in amphetamine-induced sensitization of mesolimbic dopamine function in rat. Eur J Pharmacol 282:157-167.

Berger-Sweeney J, Hohmann CF (1997) Behavioral consequences of abnormal cortical development: insights into developmental disabilities. Behav Brain Res 86:121-142.

Berridge CW, Milton E, Clark W, Roth RH (1999) Engagement in a non-escape (displacement) behavior elicits a selective and lateralized suppression of frontal cortical dopaminergic utilization in stress. Synapse 32:187-197.

Bjelke B, Andersson K, Ögren SO, Bolme P (1991) Asphytic lesion: proliferation of tyrosine hydroxylase-immunoreactive nerve cell bodies in the rat substantia nigra and functional changes in dopamine neurotransmission. Brain Res 543:1-9.

Boksa P (1997) Early developmental profiles of plasma corticosterone are altered by birth condition in the rat: a comparison of vaginal birth, Cesarean section, and Cesarean section with added anoxia. Pediat Res 41:34-43.

Boksa P, Krishnamurthy A, Sharma S (1996) Hippocampal and hypothalamic type I corticosteroid receptor affinities are reduced in adult rats born by a caesarean procedure with or without an added period of anoxia. Neuroendocrinology 64:25-34.

Brake WG, Boksa P, Gratton A (1997a) Effects of perinatal anoxia on the acute locomotor response to repeated amphetamine administration in adult rats. Psychopharmacology 133:389-395.

Brake WG, Noel MB, Boksa P, Gratton A (1997b) Influence of perinatal factors on the nucleus accumbens dopamine response to repeated stress during adulthood: an electrochemical study in the rat. Neuroscience 77:1067-1076

Brake WG, Sullivan RW, Flores G, Srivastava LK, Gratton A (1999) Neonatal ventral hippocampal lesions attenuate the nucleus accumbens dopamine response to stress: an electrochemical study in the adult rat. Brain Res 831:25-32.

Brake WG, Flores G, Francis D, Meaney MJ, Srivastava LK, Gratton A (2000) Enhanced nucleus accumbens dopamine and plasma corticosterone stress responses in adult rats with neonatal excitoxic lesions to the medial prefrontal cortex. Neuroscience 96:687-695.

Carlson JN, Fitzgerald LW, Keller RW, Glick SD (1993) Lateralized changes in prefrontal cortical dopamine activity induced by controllable and uncontrollable stress in the rat. Brain Res 630:178-187.

Carlson JN, Visker KE, Keller Jr RW, Glick SD (1996) Left and right 6-hydroxydopamine lesions of the medial prefrontal cortex differentially alter subcortical dopamine utilization and the behavioral response to stress. Brain Res 711:1-9.

Carr DB, O’Donnell P Card JP, Sesack SR (1999) Dopamine terminals in the rat prefrontal cortex synapse on pyramidal cells that project to the nucleus accumbens. J Neurosci 19:11049-11060.

Carter CS, Krener P, Chaderjian M, Northcutt C, Wolfe V (1995) Asymmetrical visual-spatial attentional performance in ADHD: evidence for a right hemispheric deficit. Biol Psychiatry 37:789-797.

Casey BJ, Castellanos FX, Giedd JN, Marsh WL, Hamburger SD, Schubert AB, Vauss YC, Vaituzis AC, Dickstein DP, Sarfatti SE, Rapoport JL (1997) Implication of right frontostriatal circuitry in response inhibition and attention-deficit/hyperactivity disorder. J Am Acad Child Adolesc Psychiatry 36:374-383. 
Castellanos FX (1997) Toward a pathophysiology of attention-deficit/hyperactivity disorder. Clin Pediat 37:381-393.

Cook Jr EH, Stein MA, Krasowski MD, Cox NJ, Olkon DM, Kieffer JE, Leventhal BL (1995) Association of attention-deficit disorder and the dopamine transporter gene. Am J Human Genet 56:993-998.

Davis KL, Kahn RS, Ko G, Davidson M (1991) Dopamine in schizophrenia: a review and reconceptualization. Am J Psychiatry 148:1474-1486.

Dell'Anna ME, Calzolari S, Molinari M, Iuvone L, Calimici R (1991) Neonatal anoxia induces transitory hyperactivity, permanent spatia memory deficits and CA1 cell density reduction in developing rats. Behav Brain Res 45:125-134.

Dell'Anna E, Chen Y, Engidawork E, Andersson K, Lubec G, Luthman J, Herrera-Marschitz M (1997) Delayed neuronal death following perinatal asphyxia in the rat. Exp Brain Res 115:105-115.

Deutch AY (1992) The regulation of subcortical dopamine systems by the prefrontal cortex: interactions of central dopamine systems and the pathogenesis of schizophrenia. J Neural Transm Suppl 36:61-89.

Doherty MD, Gratton A (1992) High-speed chronoamperometric measurements of mesolimbic and nigrostriatal dopamine release associated with repeated daily stress. Brain Res 586:295-302.

Doherty MD, Gratton A (1996) Medial prefrontal cortical D1 receptor modulation of the meso-accumbens dopamine response to stress: an electrochemical study in freely-behaving rats. Brain Res 715:86-97.

Doherty MD, Gratton A (1997) NMDA receptors in nucleus accumbens modulate stress-induced dopamine release in nucleus accumbens and ventral tegmental area. Synapse 26:225-234.

El-Khodor BF, Boksa P (1997) Long-term reciprocal changes in dopamine levels in prefrontal cortex versus nucleus accumbens in rats born by Caesarean section compared to vaginal birth. Exp Neurol 145:118-129.

Ernst M, Zametkin AJ, Matochik JA, Jons PH, Cohen RM (1998) DOPA decarboxylase activity in attention deficit hyperactivity disorder adults. J Neurosci 18:5901-5907.

Fuster JM (1997) The prefrontal cortex: anatomy, physiology, and neuropsychology of the frontal lobe. New York: Lippencott-Raven.

Gainetdinov RR (1999) Role of serotonin in the paradoxical calming effect of psychostimulants on hyperactivity. Science 283:397-401.

Geshwind N, Galaburda AM (1987) Cerebral lateralization: biological mechanisms, associations, and pathology. Cambridge, MA: MIT.

Gill M, Daly G, Heron S, Hawi Z, Fitzgerald M (1997) Confirmation of association between attention deficit disorder and a dopamine transporter polymorphism. Mol Psychiatry 2:311-313.

Glick SD, Raucci J, Wang S, Keller Jr RW, Carlson JN (1994) Neurochemical predisposition to self-administer cocaine in rats: individual differences in dopamine and its metabolites. Brain Res 653:148-154.

Gould E, Wooley C, McEwen BS (1991a) Adrenal steroids regulate postnatal development of the rat dentate gyrus. I. Effects of glucocorticoids on cell death. J Comp Neurol 313:479-485.

Gould E, Wooley C, Cameron HA, Daniels DC, McEwen BS (1991b) Adrenal steroids regulate postnatal development of the rat dentate gyrus. II. Effects of glucocorticoids and mineralocorticoids on cell birth. J Comp Neurol 313:486-493.

Günther-Genta F, Bovet P, Hohfield P (1994) Obstetric complications and schizophrenia. A case-control study. Br J Psychiatry 164:165-170.

Hales KA, Morgan MA, Thurnau GR (1993) Influence of labor and route of delivery on the frequency of respiratory morbidity in term neonates. Int J Gynecol Obstet 43:35-40.

Harfstrand A, Fuxe K, Cintra A, Agnati LF, Zini I, Wikstrom A, Okret S, Yu Z, Goldstein M, Steinbusch H, Verhofstad A, Gustafsson J (1986) Glucocorticoid receptor immunoreactivity in monoaminergic neurons of rat brain. Proc Natl Acad Sci USA 83:9779-9783.

Hartsough CS, Lambert NM (1985) Medical factors in hyperactive and normal children: prenatal, developmental, and health history findings. Am J Orthopsychiatry 55:190-201.

Heilman KM, Voeller KKS, Nadeau SE (1991) A possible pathophysiologic substrate of attention deficit hyperactivity disorder. J Child Neurol 6:S76-S81.

Hershkowitz M, Grimm VE, Speiser Z (1983) The effects of postnatal anoxia on behavior and on the muscarinic and beta-adrenergic receptors in the hippocampus of the developing rat. Brain Res 283:147-155.

Jilek L (1970) The reaction and adaptation of the central nervous system to stagnant hypoxia and anoxia during ontogeny. In: Developmenta neurobiology (Himwich WD, ed), pp 391-420. Springfield: Thomas.

Katz JL, Izenwasser S, Terry P (2000) Relationships among dopamine transporter affinities and cocaine-like discriminitive-stimulus effects. Psychopharmacology 148:90-98.

King JA, Barkley RA, Barrett S (1998) Attention-deficit hyperactivity disorder and the stress response. Biol Psychiatry 44:72-74.

Kubos KL, Pearlson GD, Robinson RG (1982) Intracortical kainic acid induces an asymmetrical behavioral response in the rat. Brain Res 239:303-309.

Lewis SW, Murray RM (1987) Obstetric complications, neurodevelopmental deviance, and risk of schizophrenia. J Psychiat Res 21:413-421.

MacLusky NT, Lieberberg I, McEwen BS (1979) The development of estrogen receptor systems in the rat brain: perinatal development. Brain Res 178:143-160.

Maisonneuve IM, Keller RW, Glick SD (1990) Similar effects of d-amphetamine and cocaine on extracellular dopamine levels in medial prefrontal cortex of rats. Brain Res 535:221-226.

McEwen BS (1992) Steroid hormones: effect on brain development and function. Hormone Res 37:1-10.

Meaney MJ, Sapolski RM, Aitken DH, McEwen BS (1985) [3H]dexamethasone binding in the limbic brain of the fetal rat. Dev Brain Res 23:297-300.

Milberger S, Biederman J, Farone SV, Guite J, Tsuang MT (1997) Pregnancy, delivery and infancy complications and attention-deficit hyperactivity disorder: issues of gene-environment interaction. Biol Psychiatry 41:65-75.

Mitchell JB, Gratton A (1992) Partial dopamine depletion of the prefrontal cortex leads to enhanced mesolimbic dopamine release elicited by repeated exposure to naturally reinforcing stimuli. J Neurosci 12:36093618.

Murphy BL, Arnsten AF, Goldman-Rakic PS, Roth RH (1996) Increased dopamine turnover in the prefrontal cortex impairs spatial working memory performance in rats and monkeys. Proc Natl Acad Sci USA 93:1325-1329.

Nielsen DM, Crosley KJ, Keller Jr W, Glick SD, Carlson JN (1999) Left and right 6-hydroxydopamine lesions of the medial prefrontal cortex differentially affect voluntary ethanol consumption. Brain Res 823:59-66.

Nigg JT, Swanson JM, Hinshaw SP (1997) Covert visual spatial attention in boys with attention deficit hyperactivity disorder: lateral effects, methylphenidate response and results for parents. Neuropsychologia 35:165-176.

Norman MG, Malla AK (1993) Stressful life events and schizophrenia. I. A review of the research. Br J Psychiatry 162:161-166.

Paxinos G, Watson C (1985) The rat brain in stereotaxic coordinates. New York: Academic.

Poets FC, Stebbens AV, Richard D, Southall PD (1995) Prolonged episodes of hypoxemia in preterm infants undetectable by cardiorespiratory monitors. Pediatrics 95:860-863.

Puumala T, Sirviö J (1998) Changes in activities of dopamine and serotonin in the frontal cortex underlie poor choice accuracy and impulsivity of rats. Neuroscience 83:489-499.

Pycock CJ, Carter CJ, Kervin RW (1980) Effect of 6-hydroxydopamine lesions of the medial prefrontal cortex on neurotransmitter systems in subcortical sites in the rat. J Neurochem 34:91-96.

Robinson RG (1979) Differential behavioral and biochemical effects of right hemispheric cerebral injections in the rat. Science 205:707-710.

Robinson RG, Stitt TG (1981) Intracortical 6-hydroxydopamine induces an asymmetrical behavioral response in the rat. Brain Res 213:387-395.

Rodriguez M, Martin L, Santana C (1994) Ontogenic development of brain asymmetry in dopaminergic neurons. Brain Res Bull 33:163-171.

Romijin HJ, Hofman MA, Gramsbergen A (1991) At what age is the developing cerebral cortex of the rat comparable to that of the full-term newborn human baby? Early Hum Dev 26:61-67.

Rosin DL, Clark WA, Goldstein M, Roth RH, Deutch AY (1992) Effects of 6-hydroxydopamine lesions of the prefrontal cortex on tyrosine hydroxylase activity in mesolimbic and nigrostriatal dopamine systems. Neuroscience 48:831-839.

Speiser Z, Korczyn AD, Teplitzky I, Gitter S (1983) Hyperactivity in rats following postnatal anoxia. Behav Brain Res 7:379-382.

Speiser Z, Amitzi-Sonder J, Gitter S, Cohen S (1988) Behavioral differences in the developing rat following postnatal anoxia or postnatally injected AF-64A, a cholinergic neurotoxin. Behav Brain Res 30:89-94.

Sullivan RM, Gratton A (1998) Relationships between stress-induced increases in medial prefrontal cortical dopamine and plasma corticosterone levels in rats: role of cerebral laterality. Neuroscience 83:81-91.

Sullivan RM, Gratton A (1999) Lateralized effects of medial prefrontal cortex lesions on neuroendocrine and autonomic stress responses in rats. J Neurosci 19:2834-2840.

Sullivan RM, Szechtman H (1995) Asymmetrical influence of mesocortical dopamine depletion on stress ulcer development and subcortical dopamine systems in rats: implications for psychopathology. Neuroscience 65:757-766.

Varlinskaya EI, Petrov ES, Robinson SR, Smotherman WP (1995) Asymmetrical development of the dopamine system in the fetal rat as indicated by lateralized administration of SKF-38393 and SCH23390. Pharmacol Biochem Behav 50:359-367.

Verdoux H, Bourgeois M (1993) A comparative study of obstetric history in schizophrenics, bipolar patients and normal subjects. Schizophr Res 9:67-69.

Vignon J, Pinet V, Cerruti C, Kamenka JM, Chicheportiche R (1988) $\left[{ }^{3} \mathrm{H}\right] N$-[1-(-2-benzo(b)thiophenyl)cyclohexyl]piperideine $\left(\left[{ }^{3} \mathrm{H}\right] \mathrm{BTCP}\right)$ : a new phencyclidine analog selective for the dopamine uptake complex. Eur J Pharmacol 148:427-436.

Weinberger DR (1987) Implications of normal brain development for the pathogenesis of schizophrenia. Arch Gen Psychiatry 44:660-669.

Wightman RM, Zimmerman JB (1990) Control of dopamine extracellular concentration in rat striatum by impulse flow and uptake. Brain Res Rev $15: 135-144$

Williams GV, Goldman-Rakic PS (1995) Modulation of memory fields by dopamine D1 receptors in prefrontal cortex. Nature 376:572-575. 